\title{
ANTEROGRADE AND RETROGRADE MEMORY IMPAIRMENT IN CHRONIC AMNESIA
}

\author{
Larry R. Squire and Pamela C. Slater \\ Psychology Service, Veterans Administration Hospital, San Diego and \\ Department of Psych iatry, University of California at San Diego, La Jolla, California, U.S.A.
}

(Received 6 October 1977)

\begin{abstract}
Tests of new learning capacity and remote memory were given to the chronic amnesic patient (N.A.) who sustained a stab wound to the basal brain in 1960. N.A.'s persisting defect in new learning was demonstrated with several tests, including a distractor test of short-term memory. These results are discussed in the light of previous findings in amnesic patients with distractor tests. N.A.'s remote memory was markedly impaired for the period since 1960 , but normal for the period prior to 1960 . This discontinuity between premorbid and postmorbid memory, also reported for the well-known amnesic H.M., favors the view that amnesia represents a defect in the formation of enduring memory rather than a general defect in retrieval.
\end{abstract}

BRAIN injury or disease can sometimes affect human memory in a relatively circumscribed way, without apparent loss in other cognitive functions. Such instances of amnesia have consequently been of special interest in discussions of the structure of human memory and its neurologic basis. In recent years there has been disagreement about what constitutes the correct description of some aspects of amnesia. For example, amnesic patients with Korsakoff psychosis have sometimes been described as normal and sometimes as deficient in short-term memory tasks $[1,2]$. There have also been divergent findings concerning the status of memory for events that occurred long before the onset of amnesia.

In the case of remote memory, newly developed tests [3-5] indicate that loss of memories acquired many years before the onset of amnesia can occur in Korsakoff patients [6], in psychiatric patients receiving electroconvulsive therapy (ECT) [7-9], and in patients with diencephalic tumor [10]. Yet, on the basis of informal interviews, the noted patient H.M. [11] appears to have normal premorbid memory, except for the period 1-3 yr prior to the onset of his amnesia in 1953 [12]. Recently, objective remote-memory tests have confirmed that H.M. has good remote memory for events of the $1920 \mathrm{~s}, 1930 \mathrm{~s}$, and $1940 \mathrm{~s}$ [13]. These results, taken together, suggest that H.M. may differ from other groups of amnesic patients with respect to premorbid memory.

H.M. has long been considered a paradigmatic example of the amnesic syndrome, because of the remarkably circumscribed nature of his memory impairment. In view of the apparent differences between H.M. and other amnesic populations in premorbid memory, it would be of considerable interest to evaluate this dimension of memory in other patients whose amnesia is relatively pure. Finally, in view of the conflicting findings with shortterm memory tasks among different populations of Korsakoff patients [1, 2], it would also be of interest to evaluate short-term memory in other amnesic patients.

We have therefore evaluated the performance of the patient N.A., originally described by Teuber, Milner and Vaughan [14]. N.A. has been amnesic since incurring a stab 
wound to the midline of the basal brain in 1960 as a result of a fencing accident. His intellectual capacity is in the bright-normal range, and he has no known cognitive dysfunction except amnesia. Tests of new learning capacity (short-term memory) were administered to N.A., to a group of patients receiving electroconvulsive therapy, and to a control group. Tests of remote memory for events that occurred in the $1950 \mathrm{~s}, 1960 \mathrm{~s}$, or 1970 s were administered to N.A. and to two different control groups matched to N.A. for age, intellectual ability, and educational background.

\section{METHOD}

Subjects. $-N . A$.

This cuse has been described previously in considerable detail [14]. In December 1960, while stationed in the Azores, this individual sustained a stab wound to the brain with a miniature fencing foil. The foil entered the right nostril and took a path upward and to the left, tearing the dura above the tuberculum sellae. The puncture apparently involved the third ventricular region, but the precise location of damage in this case is not known. By one month after the accident he was alert, oricnted, and without any sensory or motor disturbances, except for a paralysis of upward gaze. In the years since his injury, he has scored well above average on the Wechsler Intelligence Scale (118 in 1964 [14]; 124 in 1975), and has surpassed most normal subjects in a variety of perceptual tasks [14]. By contrast, he continues to exhibit difficulty in remembering everyday events and has not been employed since his accident. In its present stable condition, N.A.'s amnesia is somewhat less severe than that described for other globally amnesic patients (e.g. [12]). For example, he can find his way home by car from nearby towns, and can often recognize new acquaintances (though he may not recall their names). For the present study N.A. was tested on several occasions from February 1975 to June 1976.

\section{Normal control groups}

For miost of the tests, the control group for N.A. consisted of a group of 10 male hospital employees matched to him with respect to age (mean $=34.5 \mathrm{vs} 37$ for N.A.), years of education (mean $=14.4 \mathrm{vs} 13$ for N.A.), and intelligence test scores (mean information subtest score [W.A.I.S.] $=23.8$ vs 22 for N.A.; mean vocabulary subtest score [W.A.I.S.] $=59.5$ vs 66 for N.A.). For the current events tests, the control group consisted of 7 male inpatients at the San Diego Veterans Hospital'(mean age $=37.0$; mean yr of cducation $-14 \cdot 0$; information subtest scorc $=21 \cdot 7$; vocabulary subtest score $=60 \cdot 3$ ).

\section{Psychiatric control group tested following ECT}

Memory tests were also given to 13 psychiatric inpatients who had been prescribed a coursc of bilateral electroconvulsive therapy (ECT) for relief of depressive illness. These patients ( 8 female) were between the ages of 20 and 64 (mean $=42.5$ ) with a mean of $13.5 \mathrm{yr}$ of education. None of the patients had received ECT during the previous 12 months, and 9 had not received ECT before. ECT was administered as described previously [15]. Patients were tested beginning 2-3 hr after the first treatment of the series and again 4-5 days later, $2-3 \mathrm{hr}$ after the third treatment of the series. By 2-3 hr after ECT, patients are recovered from the acute confusional state and perform normally on standard tests of intellectual capacity $[7,8]$.

\section{Memory tests}

I. New learning capacity. (a) Story recall: A short paragraph from the Guild Memory Test [16] was read to the subject with the instruction, "When I am finished I want you to tell me as much of it as you"can remember". Immediately after reading the paragraph, subjects were told, "Begin at the beginning and tell me everything you can remember of what I read". Recall was always tested again $12 \mathrm{~min}$ later. The story was divided into 20 segments, and the score was the number of segments recalled. N.A. was tested on 2 occasions 4 months apart. Control subjects were tested once.

(b) Short-term memory distractor test: The subject was shown a consonant trigram, distracted for a variable interval $(0,3,9$, or $18 \mathrm{sec})$, and then asked to recall the consonants. The procedure followed the technique described by CERMAK, BuTTERS and GoODGLASS [17], except that the distractor procedure required subjects to count backwards by ones starting with a number between 93 and 109 . Subjects received 8 trials at each retention interval, and their score was the number of consonants recalled correctly. N.A. was given this test on two occasions 4 months apart. Control subjects were tested once.

(c) Memory for geometric figures: Subjects were asked to copy the Rey-Osterrieth figure, an intricatc geometric diagram [18], taking care to include all line segnents. This test was administered to N.A. in 1966 [14], and has becn uscd cxtensively in the evaluation of patients after unilateral temporal lobectomy [19]. Forty minutes to $1 \mathrm{hr}$ after copying the figure, subjects were asked to reproduce it from memory. The score 
on this test is the number of properly located line segments. N.A. was given this test on 3 different occasions, with an interval of at least 4 months between sessions. Control subjects were tested once.

(d) Spatial memory: Subjects attempted to remember the position of a small circle located along an 8 in. horizontal line, following the procedure described by MiLNER [12]. Subjects inspected the circle on the line for $2 \mathrm{sec}$, and then were distracted for 6,12 , or $24 \mathrm{sec}$ by arranging strings of random digits into numerical order. Then subjects marked on a different line the remembered position of the circle. Twenty-four trials were given, with 8 trials at each of the three retention intervals. The score on each trial was the distance (in $\mathrm{mm}$ ) between the position of the originally presented circle and the position of the circle as marked by the subject. N.A. was given this test on 2 occasions 4 months apart. Control subjects were tested once.

(e) Paired associate learning: This test assessed verbal learning with and without instructions in visual imagery, following the technique described by JoNes [20]. The test consisted of 2 lists of 10 word-pairs. Each word had a Thorndike-Lorge frequency rating of AA [21] and an imagery rating of 6 or higher on a 7-point scale [22]. List I was the without-imagery condition. Ten word-pairs were presented three times at a rate of $8 \mathrm{sec} /$ pair. Each presentation of the list was followed by a cued recall procedure (i.e. the subject attempted to recall the second word of the pair when presented with the first word of the pair). List II was the imagery condition. The subject was told that he would be shown a "memory trick" to improve his score. When the list was presented for the first time, a visual image was described and the subject was shown a cartoon drawing. For example, the pair "boy-water" was accompanied by the statement, "Try to imagine a boy playing in water" and a drawing was shown of a boy playing in water. The word pairs were presented two additional times without an accompanying drawing, and subjects were told to imagine the pictures they had previously been shown. Recall was tested after each of the three presentations.

II. Remote memory. Using methods described previously [4, 7], 74 cvents were selected that occurred between 1950 and 1975, and 31 television programs were selected that broadcast for one-year between 1955 and 1974. Based on this matcrial, a multiple-choice test was constructed with four alternatives. For the public events test, there were 23 questions about events that occurred 1950-1959, 26 questions about events that occurred 1960-1969, and 25 questions about events that occurred 1970-1975. For the television test there were 14 questions about the period 1955-1959, 7 questions about the period 1961-1962, and 10 questions about the period 1973-1974. Sample questions appear in Table 1. The order of the questions was random with respect to the time period during which the event occurred.

Next, a free recall test was given based on the same public events and television programs (Table 1). For the public events test, subjects were read an identifying fact about each event and then were asked specific questions designed to elicit as much information as possible about that event. For the television test, subjects were given the name of each program and then were asked to tell in turn everything they could remember about the plot, the characters, the setting, details of episodes, and names of actors. All responses were recorded, transcribed, and scored according to how many accurate details could be recalled for each decade. To determine the reliability of this scoring procedure, 4 trained raters independently scored the transcribed responses about 1973-1974 television programs for the control subjects. The number of facts credited to each subject was quite similar across raters, and in no case did the total number of facts computed by a rater deviate more than $8 \%$ from our own estimate.

Table I. Sample questions

Recognition

1. What was the S.L.A.? (1970s)

(a) a secret intelligence agency

(b) a supersonic airliner

(c) a violent revolutionary group

(d) a radical movement in Britain

2. Which of the following was a T.V. show? (1974)
(a) Sam and Susan
(b) The Problem with Girls
(c) My Sister Mary
(d) The Night Stalker

Detail recall.

1. The S.L.A. was a violent revolutionary group.

(a) Name anyone you can who was connected with the S.L.A.

(b) Why did the S.L.A. become well known?

(c) What else can you tell me about the S.L.A.?

2. The Night Stalker was a T.V. program.

(a) What was it about?

(b) Can you describe any of the characters?

(c) Tell me as much as you can about the setting for this show

(d) Can you remember any specific episodes?

(e) Do you remember the names of any of the actors?

(f) What else can you tell me about The Night Stalker? 


\section{RESULTS}

New learning capacity

Table 2 indicates that N.A. was markedly impaired in recall of a short paragraph after a delay of $12 \mathrm{~min}$. He remembered having been read a story but could not recall any information about it on any of the three occasions on which this test was given. Figure la shows performance on the short-term memory distractor for control subjects, for the patient N.A., and for patients receiving ECT. N.A.'s performance on this test was similar to the performance of patients who had received bilateral ECT 2-3 hr prior to testing. Patients receiving ECT performed significantly worse than control subjects $(F=15 \cdot 5$, $d f=1,21, P<0.01$ ). This finding is consistent with the common observation that during the hours after ECT, memory test scores are below pre-ECT scores and below the scores of matched subjects not receiving ECT [23-25].

Table 2. Verbal and nonverbal memory

\begin{tabular}{|c|c|c|c|c|}
\hline & \multicolumn{2}{|c|}{ Story recall } & \multirow[b]{2}{*}{ Copy } & \multirow{2}{*}{$\begin{array}{c}\text { Diagram reproduction } \\
\text { (maximum score }=36 \text { ) } \\
\text { Delayed } \\
\text { recall }\end{array}$} \\
\hline & Immediate & Delayed & & \\
\hline $\begin{array}{l}\text { N.A.* } \\
\text { Control } S \mathrm{~s}(N=9)\end{array}$ & $\begin{array}{c}4 \cdot 5 \\
8 \cdot 6 \pm 1 \cdot 0\end{array}$ & $\begin{array}{c}0 \\
7 \cdot 1+1 \cdot 1\end{array}$ & $\begin{array}{c}35 \cdot 3 \\
32 \cdot 1 \div 0 \cdot 9\end{array}$ & $\begin{array}{c}14 \cdot 7 \\
24 \cdot 3+1 \cdot 7\end{array}$ \\
\hline
\end{tabular}

* Scores arc averaged from three testing sessions.
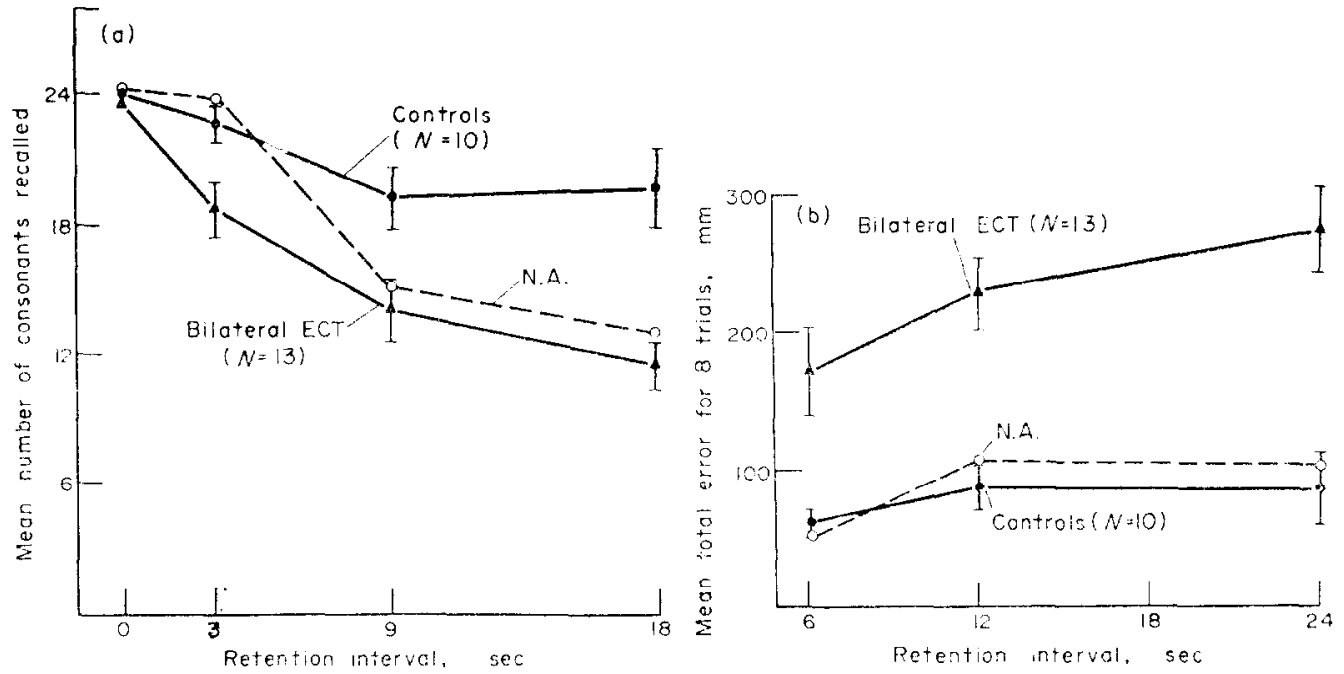

FIG. 1. Recall of verbal or nonverbal material by control $S$ s, patients receiving ECT, and the patient N.A. Scores for patients receiving ECT are averages of two tests given $2-3 \mathrm{hr}$ after the first and $2-3 \mathrm{hr}$ after the third treatments in the series. Scores for N.A. are averages of two tests about 4 months apart. (a) Mean number of consonants recalled correctly as a function of learning-retention interval. The maximum possible score at each interval is 24 . (b) Recall of visual location as a function of learning retention interval. The score at each interval is the total error (in $\mathrm{mm}$ ) for 8 trials. Scores for control $S$ s are meams \pm S.E.M.

Table 2 shows N.A.'s score for reproduction of a geometric diagram after a 40 min delay. His average scores from three separate sessions was $14 \cdot 7$, close to the score of 17 that he 
obtained in 1968 [14]. This score was outside the range of scores obtained by the 9 control subjects who took this test. Figure $1 \mathrm{~b}$ shows performance on the spatial memory test for control subjects, for N.A., and for patients receiving ECT. On this test, N.A. did rather well, performing only slightly below the control mean. Patients receiving bilateral ECT performed significantly more poorly than normal subjects $(F=19 \cdot 7, d f=1,21, P<0.01)$.

The score for paired associate learning was the number of words recalled out of 10 on each of three learning trials. In the without-imagery condition (List 1), N.A.'s score on three successive learning trials was $0,0,2$. Six control $S$ s averaged $6 \cdot 0,9 \cdot 2,9 \cdot 7$. When mnemonics were provided (List II), N.A.'s score improved somewhat $(3,4,4)$. Controls averaged 9.0, $9 \cdot 8,9 \cdot 8$.

\section{Remote memory}

Performance of the control groups and of N.A. on multiple-choice tests about public events and television programs is shown in Fig. 2. On both tests, N.A. scored close to the control subjects, exceeding their average score for some time periods. It must be concluded that N.A.'s performance on the multiple-choice tests was rather good, considering his difficulty in remembering day-to-day events.
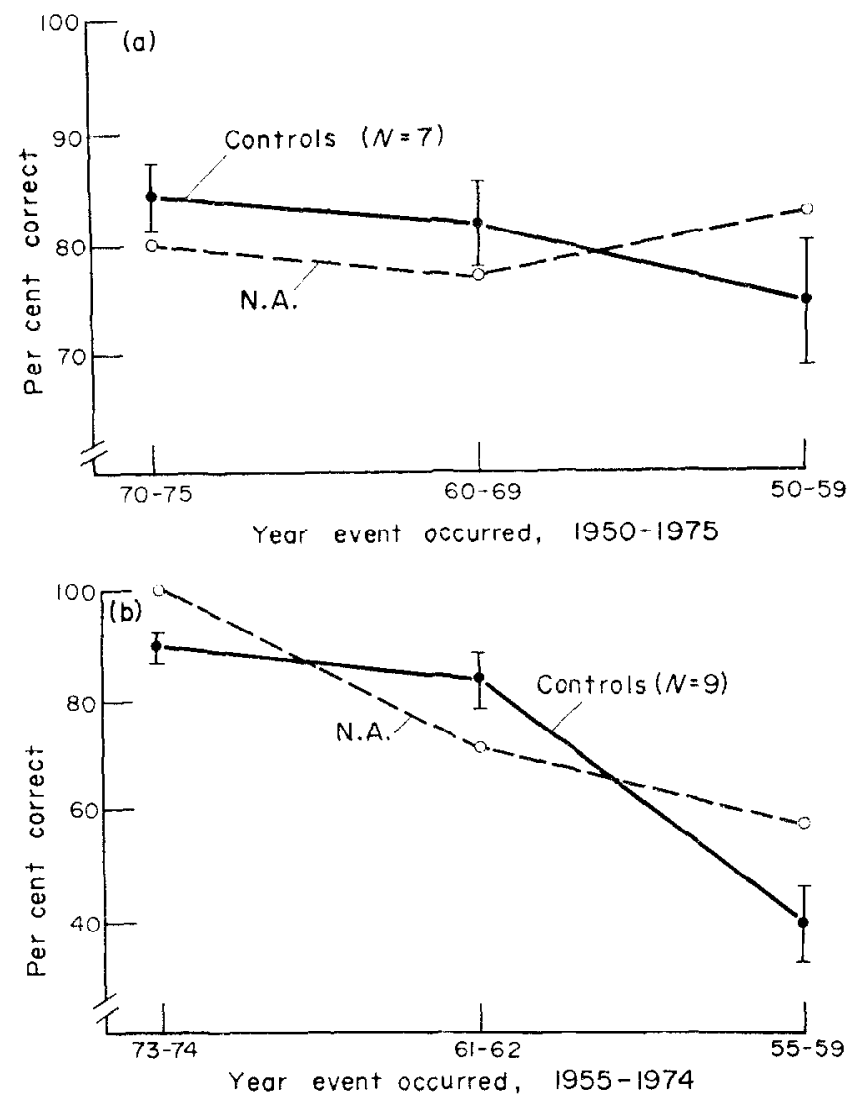

Fig. 2. Results for multiple-choice tests about public events (a) that occurred between 1950 and 1975 and television programs (b) broadcast for 1 yr between 1955 and 1974. Scores for control $S$ s are means \pm S.E.M. 
In contrast to multiple-choice tests, recall tests involving these same public events and television programs provided a rather sensitive measure of N.A.'s amnesia, For recall of both public events and television programs, N.A. was considerably below the controlgroup mean for the period since 1960 (Fig. 3). For public events, he was able to recall 17 details about the 1960s and 10 details about the 1970s. Both these scores were below the lowest control-subject score. For television programs, N.A. recalled 13 details about the 10 programs that broadcast 1973-1974, and 1 detail about the 7 programs that broadcast 1961-1962. Only one control subject scored lower in either time period.
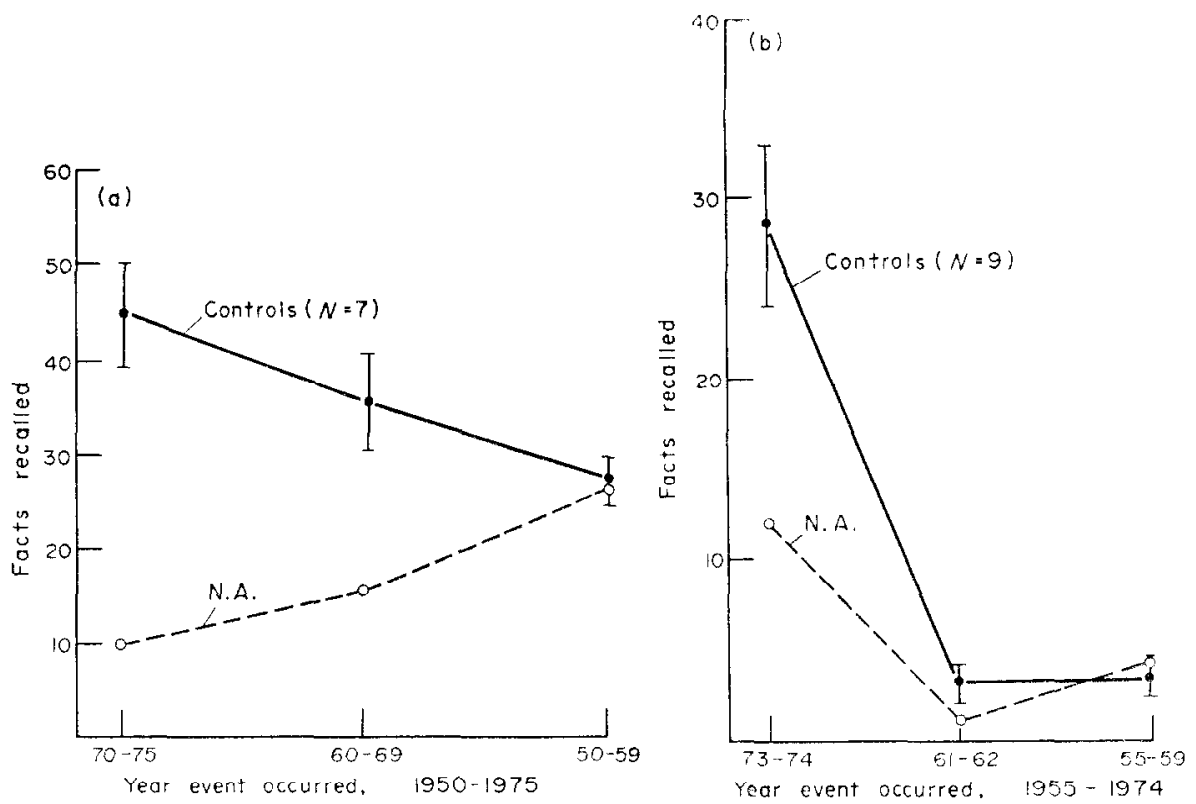

FIG. 3. Number of facts recalled about public events (a) that occurred from 1950 to 1975 or television programs (b) that broadcast for $1 \mathrm{yr}$ from 1955 to 1974 . For public events the number of questions for the 1950s, 1960, and 1970s was 23, 26, and 25, respectively. For television programs, the corresponding numbers were 14,7 , and 10 . The corrected score for public events is the number of details recalled/25 events. The corrected scorc for television programs is the number of details recalled per 10 programs. Scores for control $S$ s are means \pm S.E.M.

For the period 1950-1959, prior to his accident, N.A. was able to recall events as well as control subjects. Specifically, he was able to recall 25 details about public events and 6 details about television programs. The corresponding means for the control group were 25.7 and 5.0. These results, taken together, suggest that N.A.'s memory for events that occurred since his accident in 1960 is markedly impaired, and that his memory is normal or very close to normal for events that occurred before 1960 .

\section{DISCUSSION}

The present findings make several points about this case in particular and about amnesia in general. These involve (1) the nature and severity of the memory defect in this patient currently, as compared to 1967 when he was last studied [14]; (2) the performance of am- 
nesic patients on distractor tests of short-term memory; (3) the availability of premorbid memory in chronic anterograde amnesia.

\section{N.A.: Current status}

The present results demonstrated that N.A. was impaired in verbal memory as well as in nonverbal memory, verbal memory being affected to a greater extent. He scored as poorly on a verbal memory test as patients receiving bilateral ECT, but scored much better on a nonverbal memory test than patients receiving ECT. This same asymmetry of verbal and nonverbal memory capacity was described in the original report of this patient [14], and thus appears to be a persistent feature of his amnesia. N.A. was able to improve somewhat in paired-associate learning with the use of imagery, perhaps because his non-verbal memory capacity is only mildly impaired. More severely amnesic patients like H.M. cannot profit from imagery [20]. Korsakoff patients can use imagery to improve paired-associate learning [26], but may not be able to use it in more complex tasks [27].

When N.A. was last studied, a number of observations suggested that he had an unusual degree of pain tolerance [14]. In addition, there was reason to suspect that he might be impotent. However, in 1976 N.A. obtained a normal score on the tourniquet test of pain tolerance, a standardized procedure for the measurement of clinical pain [28]. Furthermore, according to recent clinical interviews N.A. (though not sexually active) does have sexual interests and is capable of ejaculation. These findings indicate that there is no necessary association between amnesia and either pain insensitivity or impotence. The latter symptoms have apparently disappcared, lcaving his amnesia as a circumscribed defect uncomplicated by other neurological disorders.

\section{Amnesia and distractor tests}

Both N.A. and patients receiving bilateral ECT performed poorly on the short-term memory distractor test. This finding adds to the list of etiologically divergent conditions in which performance is impaired on this task. Thus, Korsakoff patients [17], patients who have sustained left temporal lobectomy [29], patients receiving ECT [30], the patient H.M. [31], and the patient N.A. are all impaired when asked to retain newly learned verbal material for several seconds in the face of distraction. A single exception to this pattern of findings is the report that a mixed group of 6 amnesic patients performed normally on the distractor test [2]. As discussed previously [1, 32], these patients may have performed well because their amnesia was mild or because the modified distraction procedure employed with these patients may have permitted rehearsal. Considering the present findings, together with previously reported work by other investigators, it seems very likely that impairment on distractor tests of the type described here is a typical feature of most forms of amnesia.

\section{Ammesia and premorbid memory}

Despite his difficulty in learning new material since his accident in 1960, N.A. performed normally on two multiple-choice tests concerning events that occurred during the past $25 \mathrm{yr}$ (1950-1975). He apparently has been able to acquire enough new information to perform adequately on these recognition tests. Such tests are known to be sensitive to the acute amnesia associated with bilateral ECT [7], but apparently are not sensitive enough to detect N.A.'s chronic anterograde amnesia. Thus, questions about past events may need to be more probing and specific to detect impaired memory. For example, on one multiplechoice test, N.A. was able to choose correctly from four alternatives that the S.L.A. was a 
violent revolutionary group (see Table 1). Later, however, he was unable to answer any specific questions about the S.L.A. or to provide any additional information about it. Recognition tests can also be sensitive to amnesia when they are based on details about past events [33].

In contrast to his difficulty in remembering events that occurred since 1960, N.A.'s ability to provide details about events that occurred prior to 1960 appeared quite normal. On both the test of public events and the test of former television programs, his score for the period 1950-1959 was close to the control group average. Taken together, the results for the remote memory tests indicate that N.A. has poor recall of postmorbid events and good recall of premorbid events. These findings agree substantially with the conclusions of a similar assessment carried out with the well-known amnesic patient H.M. [13]. Thus, both N.A. and H.M. have a discontinuity betwcen premorbid and postmorbid memory, with premorbid memories relatively well preserved. Of course, some degree of retrograde amnesia could exist, but cover too short a period to be detected by available remote memory tests. Informal interviews suggest that H.M. has some retrograde amnesia for the period 1-3 yr prior to his surgery [12]. Similarly, it is our impression that N.A. has difficulty remembering events during the period $1 / 2-1-1 / 2$ yr prior to his accident.

The finding that premorbid memory is normal for the most part in both N.A. and H.M. suggests that normal premorbid memory may be typical in cases of chronic anterograde amnesia. Patients exhibiting extensive retrograde memory impairment $[6,7,10]$ might have cognitive dysfunction in addition to amnesia, or might have a more severe amnesic syndrome (i.c. greater anterograde amnesia) than patients not exhibiting extensive retrograde memory impairment. In any case, the conclusion that premorbid memory can be normal argues against the interpretation of amnesia as a general defect in retrieval [34], since a retrieval defect should involve premorbid as well as postmorbid memories. Accordingly, all available evidence from two carefully studied cases of chronic amnesia (H.M. and N.A.) points to a clear dissociation between premorbid and postmorbid memory capacity, and supports the related hypothesis that chronic amnesia involves primarily a defect in committing day-to-day events to memory.

Acknowlelgements--This research was supported by the Mcdical Rescarch Scrvice of the Veterans Administration and by NIMH Grant No. 24600. We thank GRETCHEN TIMMERMANs of the Psychology Service, San Diego Veterans Hospital, for assessing the patient's pain tolerance and Dr. Lowell Storms of the Psychology Service for conducting clinical intcrviews. We also thank Drs. LyTin Nadel and C. Douglas WETZEL for helpful comments and criticism.

\section{REFERENCES}

1. Butters, N. and Cermak, L.S. Some comments on Warrington and Baddeley's report of normal shorttern memory in amnesic patients. Neuropsychologia 12, 283-285, 1974.

2. BADDELEY, A. D. and WArRtriton, E. K. Amnesia and the distinction between long- and shert-term memory. J. verb. Learn. verb. Behav. 9, 176-189, 1970.

3. Warrington, E. K. and Silbrrsten, M. S. A questionnaire technique for investigating very long-term memory. Quart. Il exp. Psychol. 22, 508-512, 1970.

4. Squire, L. R. and Slater, P. C. Forgetting in very long-term memory as assessed by an improved questionnaire technique. J.exp. Psychol. Human Leam. Memory 104, 50-54, 1975.

5. Squire, L. R., Chace, P. M. and Slater, P. C. Assessment of menory for remote events. Psychol. Rep. 37, 223-234, 1975.

6. Sanders, H. I. and Warrington, E. K. Memory for remote events in amnesic patients. Brain 94, 661-668, 1971 .

7. Squire, L. R. A stable impairment in remote memory following clectroconvulsive therapy. Neuropsychologia 13, 51-58, 1975. 
8. Squire, L. R., Slater, P. C. and Chace, P. M. Retrograde amnesia: temporal gradient in very longterm memory following electroconvulsive therapy. Science, N.Y. 187, 77-79, 1975.

9. Squire, L. R., Slater, P. C. and Chace, P. M. Reactivation of recent or remote memory before electroconvulsive therapy does not produce retrograde amnesia. Behav. Biol. 18, 335-343, 1976.

10. Ignelzi, R. J. and SquiRe, L. R. Recovery from anterograde and retrograde amnesia following percutaneous drainage of a cystic craniopharyngioma. J. Neurol. Neurosurg. Psychiat. 39, 1231-1236, 1976.

11. Scoville, W. B. and Milner, B. Loss of recent memory after bilateral hippocampal lesions. J. Neurol. Neurosurg. Psychiat. 20, 11-21, 1957.

12. Milner, B. Disorders of Icarning and memory after temporal lobe lcsions in man. Clin. Neurosurg. 19, 421-446, 1972.

13. Marslen-Wilson, W. D. and Teuber, H.-L. Memory for remote events in anterograde amnesia: recognition of public figures from newsphotographs. Neuropsychologia 13, 353-364, 1975.

14. Teuber, H.-L., Milner, B. and Vaughan, H. G. Persistent anterograde amnesia after stab wound of the basal brain. Neuropsychologia 6, 267-282, 1968.

15. Squire, L. R., Chace, P. M. and Slater, P. C. Retrograde amnesia following electroconvulsive therapy. Nature, Lond. 260, 775-777, 1976.

16. Gilbert, J. G., Levee, R. F. and Catalano, F. L. A preliminary report on a new memory scale. Percept Motivat. Skills 27, 277-278, 1968.

17. Cermak, L. S., Butters, N. and Goodglass, H. The extent of memory loss in Korsakoff patients. Neuropsychologia 9, 307-315, 1971.

18. Osterrieth, P. Le test de copie d'une figure complexe. Archs Psychol. 30, 206--356, 1944.

19. TAYLor, L. B. Localisation of cerebral lesions by psychological testing. Clin. Neurosurg. 16, 269.287 , 1969.

20. JoNeS, M. K. Imagery as a mnemonic aid after left temporal lobectomy: Contrast between materialspecific and generalized memory disorders. Neuropsychologia 12, 21-30, 1974.

21. Thorndike, E. L. and Lorge, I. The Teacher's Word Book of 30,000 Words. Teachers College Press, New York, 1944.

22. Paivio, A., Yuille, J. C. and Madigan, S. A. Concreteness, imagery and meaningfulness values for 925 nouns. J. exp. Psychol. 76, 1-24, 1968.

23. Dornbush, R. L. and Williams, M. Memory and ECT. In Psychobiology of Convulsive Theropy, M. Fink, S. KetY, J. MCGaugh et al. (Editors), pp. 199-207. V. H. Winston \& Sons, Washington, D.C., 1974.

24. Harper, R. G. and Wiens, A. N. Electroconvulsive therapy and memory. J. nerv. Ment. Dis. 161, $245-254,1975$.

25. SQuire, L. R. and Chace, P. M. Memory functions six to nine months after electroconvulsive therapy. Archs. Gen. Psychiat. 32, 1557-1564, 1975.

26. Cermak, L. S. Imagery as an aid to retrieval for Korsakoff patients. Cortex 11, 163-169, 1975.

27. BADDELEY, A. D. and WARRiNGTON, E. K. Memory coding and amnesia. Neuropsychologia 11, 159-165, 1973.

28. Sternbach, R. A., Murphy, R. W., Timmermans, G., Greenboot, J. H. and Alceson, W. H. Measuring the severity of clinical pain. In Advances in Neurology: Pain, J. J. BonICA (Editor), Vol. 4, pp. 281-288 Raven Press, New York, 1974.

29. Mrlner, B. Hemispheric specialization: Scope and limits. In The Neurosciences, Third Study Program, F. O. Schmitt and F. G. Worden (Editors), pp. 75-89. MIT Press, Cambridge, 1972.

30. Dornbush, R., Abrams, R. and Fink, M. Memory changes after unilateral and bilateral convulsive therapy (ECT). Br. J. Psychiat. 119, 75-78, 1971.

31. Corsi, P. M. Human memory and the medial temporal region of the brain. Unpublished Ph.D. Thesis, Mcrill University, 1972.

32. Kinsbourne, M. and Wood, F. Short-term memory processes and the amnesic syndrome. In Short-Term Memory. D. Deutsch and J. A. Deursch (Editors), pp. 257-291. Academic Press, New York, 1975.

33. Squire, L. R. and Slater, P. C. Remote memory in chronic anterograde amnesia. Behav. Biol. 39, $1231-1235,1977$.

34. Warrington, E. K. and Weiskrantz, L. Amnesic syndrome: Consolidation or retrieval? Nature, Lond. 228, 628-630, 1970. 
Résumé :

On a soumis à des tests d'apprentissage de matériel nouveau et à des tests de mémoire ancienne un malade devenu amnésique (N.A.) à la suite de blessures par fleuret en 1960 de 1 a base du cerveau. Le deficit persistant d'apprentissage chez N.A. Etail démontré par plusieurs épreuves en particulier lors d'un test de mémoire à court terme avec procédure de distraction. on discute ces résultats à la lumière des constatations antérieures obtenues chez les amnésiques avec ces procédures de distraction. La mémoire ancienne de in. A. était nettement déficitaire pour la période suivant 1960 mais normale pour la période antérieure. Cette discontinuité entre mémoire prémorbide et mémoire post morbide, également prësente dans le cas fameux de H.M. est en faveur du point de vue selon lequel l'amnésie représente un déficit dans la constitution des souvenirs plutot qu'un deficit gênêral du rappel.

\section{Deutschsprachige Zusammenfassung:}

Chronisch amnestische Patienten (N. A.), die 1960 eine Stichverletzung in den Hirnstamm erlitten hatten, wurden auf ihre Fähigkeit, neu zu lernen, und auf ihr Altgedächtnis untersucht. Ein noch bestehender Mangel in Bezug auf die Lernfähigkeit ließ sich bei den chronisch amestischen Patienten mit mehrerer Tests nachweisen, darunler mit einem Test zum Kurzzeitgedächtnis bei Ablenkung. Diese Ergebnisse werden im Zusammenhang mit friheren Befunden an amnestischen Patienten mit Ablenkungs-Tests diskutiert. Das Altgedächtnis der amnestischen Patienten war deutlich beeinträchtigt für die Zeit seit 1960, dagegen normal für die Zeit vor 1960. Diese Diskontinuität zwischen prämorbidem und postmorbidem Gedächtnis, die auch von dem bekannten amrestischen Patienter h. W. berichtet wurde, spricht für die Ansicht, daß die Amnesie eine Schädigung bei der Bildung dauerhafter Gedächtnisinhalte darstell.t und nicht eine generelle Beeinträchtigung der Fähigkeit des Abrufens. 